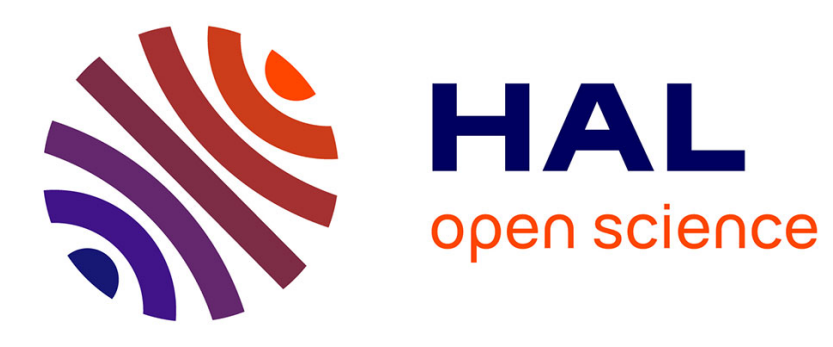

\title{
The THEMA study: a sociodemographic survey of hypercholesterolaemic individuals
}

T. Fournier, E. Bruckert, Sébastien Czernichow, A. Paulmyer, Jean-Pierre Poulain

\section{- To cite this version:}

T. Fournier, E. Bruckert, Sébastien Czernichow, A. Paulmyer, Jean-Pierre Poulain. The THEMA study: a sociodemographic survey of hypercholesterolaemic individuals. Journal of Human Nutrition and Dietetics, 2011, 24 (6), pp.572 - 581. 10.1111/j.1365-277X.2011.01168.x . hal-02644857

\section{HAL Id: hal-02644857 \\ https://hal.inrae.fr/hal-02644857}

Submitted on 28 May 2020

HAL is a multi-disciplinary open access archive for the deposit and dissemination of scientific research documents, whether they are published or not. The documents may come from teaching and research institutions in France or abroad, or from public or private research centers.
L'archive ouverte pluridisciplinaire HAL, est destinée au dépôt et à la diffusion de documents scientifiques de niveau recherche, publiés ou non, émanant des établissements d'enseignement et de recherche français ou étrangers, des laboratoires publics ou privés. 


\title{
RESEARCH PAPER
}

\section{The THEMA study: a sociodemographic survey of hypercholesterolaemic individuals}

\author{
T. Fournier, ${ }^{*}$ E. Bruckert, $\uparrow$ S. Czernichow, $\$$ A. Paulmyer $\S \&$ J. P. Poulain* \\ *Université de Toulouse, CERTOP-CNRS, UTM, Toulouse, France \\ $†$ Assistance Publique Hôpitaux de Paris, Paris, France \\ †UMR INSERM U557, INRA, CNAM, UP13, Department of Public Health, Avicenne Hospital, Bobigny, France \\ §Unilever France, Rueil-Malmaison, France
}

\author{
Keywords \\ compliance, diet, France, \\ hypercholesterolaemia, medication, \\ sociodemographic. \\ Correspondence \\ T. Fournier, Université de Toulouse, CERTOP- \\ CNRS, UTM, 5 Allées A. Machado, 31058 \\ Toulouse Cedex 9, France. \\ Tel.: +33561503554 \\ Fax: +33561504128 \\ E-mail: tristan.fournier@univ-tlse2.fr
}

doi:10.1111/j.1365-277X.2011.01168.x

\begin{abstract}
Background: Hypercholesterolaemia is estimated to affect $20 \%$ of the population, although little sociodemographic information is available on affected individuals. The present study aimed to gather relevant information and investigate social determinants of dietary compliance.

Methods: A telephone survey was carried out on a representative population sample. Quotas were applied for gender, geography and degree of urbanisation. Individuals were eligible if they were hypercholesterolaemic, and were being followed by a doctor. Sociodemographic, socioeconomic and health data were collected, as well as information about the individuals' perception of the disease, their relationship and beliefs surrounding food, and their food behaviour (shopping, cooking, eating-out, deviation from prescribed diet). The association between compliance with diet and medication was investigated.

Results: Overall, 802 individuals were included, representing $8 \%$ of those contacted, as opposed to the expected 20\%. Mean (SD) age was 60 (14.2) years, with $51 \%$ of individuals living as a couple; $48 \%$ had a good level of physical activity; $44 \%$ considered that the hypercholesterolaemia was inherited; $31 \%$ felt that the disease was normal beyond the age of 45 years. The functional and convivial aspects of eating were of more importance than that of health maintenance. Cheese was particularly likely to be eaten in dietary lapses. Of a subgroup of 729 individuals, $476(65 \%)$ took medication; of these 476 individuals, $51 \%$ complied with dietary recommendations $(P<0.05)$.

Conclusions: The key factors associated with dietary compliance in hypercholesterolaemic individuals were identified: age, sex, the perceptions of hypercholesterolaemia, and the sociocultural aspects of food. By contrast to general assumptions, both dietary and medicinal measures are practised fairly well by a large proportion of these individuals.
\end{abstract}

\section{Introduction}

Hypercholesterolaemia is a serious illness, of which the long-term effects are one of the major causes of cardiovascular disease (McQueen et al. 2008; The Emerging Risk Factors Collaboration, 2009). As such, it places an enormous burden upon health, social work and research budgets in developed countries. However, it is a disease that can be easily detected by simple blood testing, and in which sufferers can take active life-style measures to help themselves. These measures usually initially involve changes being made to the patient's diet and level of physical activity before lipid-lowering medication is used (Grundy et al. 2004; AFSSAPS, 2005).

Twenty percent of the French population is estimated to have hypercholesterolaemia (Ferrieres et al., 2009), 
although limited sociodemographic and socioeconomic data exist for this group. A qualitative sociological study (Fournier \& Poulain, 2008) concentrated on determining the reasons given by a small sample of French hypercholesterolaemic patients for not following their recommended lipid-lowering diet. Four main reasons were found: the patients' food pattern and cultural experience; their relationship with healthcare professionals; their perception of the risks associated with hypercholesterolaemia; and the social context of the eating situation. Certain foods, such as cheese, butter and processed meat (charcuterie) were identified as being particularly difficult to reduce.

Over and above the strong regional and traditional dietary habits, the French attitude to food also gives great weight to the pleasurable aspect of eating (Rozin et al., 1999; Pettinger et al., 2004), with the quality of product being considered of more importance than the quantity. It has been suggested that this attitude towards pleasure could have as much an influence on diet-dependent health as the actual dietary components (Rozin et al., 1999). This could be one explanation for the 'French paradox' (i.e. for the fact that, although the average French diet has a relatively high fat level compared to the average American diet, the French have lower levels of cardiovascular disease) (Richard, 1987; Rozin et al., 1999). This possibility underlines the importance of having an overall understanding of how individual patients relate to eating, and dietary behaviour in general.

The THEMA (Typologie d'Hypercholestérolémiques et Etude de leurs Modèles Alimentaires - Typology of hypercholesterolaemic people and study of their eating patterns) survey was developed with the aim of collecting sociodemographic and socioeconomic data from a representative sample of French hypercholesterolaemic individuals, and investigating possible social determinants of the lack of dietary compliance. The present part of the THEMA study aimed to document aspects of individuals' eating patterns, their attitudes towards food and their disease, and how often they were in contact with a doctor.

\section{Materials and methods}

\section{Subject selection}

Because a survey base did not exist, a nonrandom quota survey method was used. A private polling institute, the BVA company (Viroflay, France), conducted out anonymised telephone questionnaires on a sample of individuals representative of the French population. Because it is estimated that approximately $20 \%$ of the French population has a cholesterol level higher than that recommended (Ferrieres et al., 2009), a 20\% inclusion rate was aimed for. Quotas were applied for sex, region of residence and size of urban area, as well as whether the individual took lipid-lowering medication or not. Although the vast majority of patients being treated were given statins, no specific questions were asked regarding the type of treatment (resin, fibrate, statin or other), nor the dosage prescribed to the patients. No specific dietetic prescription was given to the patients in the present study and they only received the advice given by the general practitioner according to the French guidelines, which include mainly a reduction in saturated fats at the same time as maintaining an adequate intake of mono- and polyunsaturated fats. According to French law regulating clinical research (Loi Huriet), this survey did not require any particular ethical committee or data protection board approval.

The questionnaire was designed as an extension of qualitative sociological research that had been carried out previously. It comprised 58 closed and multiple choice questions and consisted of standard questions used in sociology to describe population sociodemographics (Desrosieres, 1998), as well as questions that were used in other studies (Poulain, 2002; Rozin et al., 2006). To check whether the questions were both comprehensible and discriminatory, they were pretested on 20 individuals (who were not included in the final sample). Finally, the overall questionnaire was validated by the multidisciplinary team involved in the present study. The questionnaire was planned to take an average of $25 \mathrm{~min}$ to complete. The BVA interviewers were trained in its use by one of the authors; this training comprised of one half-day spent reading through the questionnaire, testing it using a computer assistance system, and in the simulation of the possible responses to the multiple choice questions.

Telephone contact was made between $17.00 \mathrm{~h}$ and 19.00 h, from Mondays to Fridays, during March 2008. Individuals who had raised cholesterol and were receiving dietary advice from their doctor were included.

Eligible, consenting individuals were invited to answer further questions on several subjects, as outlined below.

\section{Sociodemographic questions}

Sociodemographic information included sex, age, living situation, level of education and socioprofessional category. Socioprofessional categories were based on the French National Institute of Statistics and Economic Studies (INSEE) groups (INSEE, 2008).

\section{Health factors}

Individuals were questioned about lipid-lowering medication intake, how long they had been aware of being hypercholesterolaemic, the presence of cardiovascular risk factors (smoking, hypertension, diabetes, family history of cardiovascular disease, personal cardiovascular incident), 
weight and height, and physical activity. Physical activity was assessed by two questions about walking and the frequency of taking part in a sporting activity: (1) 'Do you walk more than 30 min a day?' and (2) 'Do you take part in a sporting activity at least one time a week?'.

\section{Disease management}

Questions were asked on the following issues: to whom individuals gave the most confidence in the management of the disease; the information sources used; what they considered to be the best method of protecting against cardiovascular risk; and the frequency of medical consultation for the problem.

\section{Behaviour and attitudes surrounding food and eating}

Individuals chose two out of five preset responses to the question 'What does eating represent mainly for you?'. The possible responses were: (1) being with family or friends; (2) a pleasurable activity for myself; (3) a way of maintaining health and protecting myself against illness; (4) a way of expressing my ethical, political and ecological convictions; and (5) a necessary function. For analysis, these were classified as: (1) convivial, (2) hedonistic, (3) prudent, (4) political and (5) functional.

Individuals were also questioned about factors affecting food consumption, changes that would be made to food choices if more money was available, frequency of cooking and shopping for food, frequency of eating outside of the home and, if so, in what circumstances.

\section{Adherence to a lipid-lowering diet}

The following issues were treated: foods that individuals considered should be avoided or favoured; situations where deviation from a prescribed diet occurred; how the individual dealt with diet deviation; reasons for difficulty in following the diet; types of unrecommended food eaten; and cheese consumption.

Because a self-reported following of diet is likely to be biased, a separate 'compliance with diet' variable was built, using four variables: whether the individual followed a lipid-lowering diet; his/her amount of diet infringement; the difficulties encountered in adhering to the diet; and his/her hypothetical responses to a cheese-eating situation. Results were classified into compliance or noncompliance with the diet, and crossed with medication intake.

\section{Statistical analysis}

Data were excluded from individuals aged $<18$ years. Results are given as percentages and the mean. Categorical data were analysed using the chi-squared test. Statistical analysis was performed using sPss, version 14.0 (SPSS Inc., Chicago, IL, USA). $P<0.05$ was considered statistically significant.

\section{Results}

Construction of the sample

The questionnaire was answered by 802 individuals, representing an $8 \%$ inclusion rate from a total of 9599 valid telephone calls. The survey aimed to focus on French hypercholesterolaemic people who managed their disorder by dietary adjustment alone, and it was intended to include two-thirds of individuals using dietary control measures alone. However, because of recruitment difficulties, the quota of individuals taking lipid-lowering medication was increased; in the end, these individuals accounted for two-thirds of inclusions.

\section{Sociodemographic characteristics}

The mean (SD) age was 60 (14.2) years, with most individuals living as a couple. Thirty percent had only completed basic obligatory schooling, although $45 \%$ were, or had been, in the middle socioprofessional category. Fifty percent of individuals were retired (Table 1 and Fig. 1).

\section{Health factors}

Lipid-lowering medication intake varied according to age (30\% in people aged <45 years; $60 \%$ between 46 and 55 years; $71 \%$ between 56 and 65 years; 78\% between 66 and 75 years; and $80 \%>76$ years). Forty-one percent of individuals had known about their hypercholesterolaemia for over 10 years; $46 \%$ for between 1 and 10 years; and $11 \%$ for $<1$ year. Fifty-seven percent of individuals did not know their cholesterol level.

A family history of cardiovascular disease and hypertension were the most reported classical cardiovascular risk factors; the majority of individuals had a good physical activity level (Table 2). Forty-four percent of individuals considered the disease to be a family trait, with lifestyle also being considered responsible in a quarter of cases; almost one-third of individuals classified hypercholesterolaemia as normal beyond the age of 45 years (Table 3 ).

\section{Disease management}

The majority of individuals had confidence in the medical profession for management of the disease and relied on them as an information source (Table 4). Two-thirds of individuals considered themselves to be the person with the most important role to play in disease management; 
Table 1 Sociodemographic characteristics

\begin{tabular}{|c|c|}
\hline & $n(\%)$ \\
\hline \multicolumn{2}{|l|}{ Gender $(n=802)^{*}$} \\
\hline Male & $383(48)$ \\
\hline Female & $419(52)$ \\
\hline \multicolumn{2}{|l|}{ Living situation ( $n=780$ ) } \\
\hline As a couple & $401(51.4)$ \\
\hline Alone & $241(30.9)$ \\
\hline In a family & $138(17.7)$ \\
\hline \multicolumn{2}{|l|}{ Highest education ( $n=802$ ) } \\
\hline Basic obligatory schooling & $237(29.5)$ \\
\hline Secondary school & $221(27.6)$ \\
\hline College & $171(21.3)$ \\
\hline University and higher & $173(21.6)$ \\
\hline \multicolumn{2}{|c|}{$\begin{array}{l}\text { Socioprofessional categories, actual, } \\
\text { or previous if retired }(n=802)^{\dagger}\end{array}$} \\
\hline Lower & $189(23.6)$ \\
\hline Middle & $364(45.4)$ \\
\hline Upper & $152(19.0)$ \\
\hline Inactive & $96(12.0)$ \\
\hline
\end{tabular}

*Quotas were applied.

†Lower: independent farmer, self-employed craftsperson or artisan, independent shopkeeper or tradesperson, salaried service staff, factory or agricultural worker. Middle: intermediate salaried professional and paramedical professional, primary school teacher or similar, salaried employee. Upper: business owner (self-employed and with more than 10 employees), self-employed professional (except paramedical professionals), teacher (high-school and university), salaried scientist, upper level manager. Inactive: student, disabled person, houseperson.

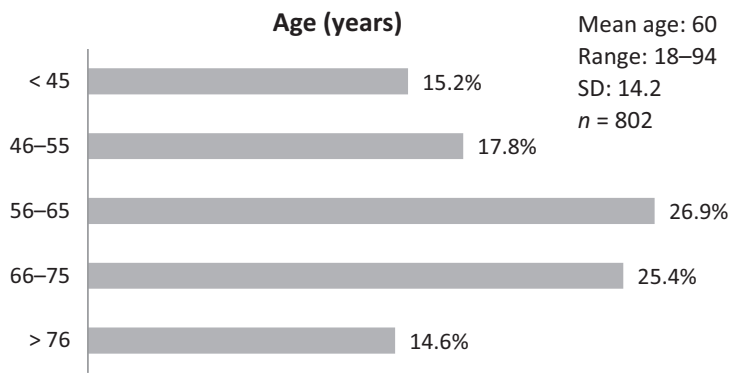

Figure 1 Age distribution.

the close circle, when it existed, had a variably helpful role to play (Table 5).

\section{Behaviour and attitudes surrounding food and eating}

The response of 'a way of expressing my ethical, political and ecological convictions' to the question 'What does eating represent mainly for you?' was almost nil, and it was therefore removed from the analysis. In the valid combined responses $(n=742)$, the combination given most frequently was 'necessary function' (first) with 'being with family or friends' (second). When the order given for
Table 2 Classical cardiovascular risk factors, body mass index (BMI) and physical activity

\begin{tabular}{|c|c|}
\hline & $n(\%)$ \\
\hline \multicolumn{2}{|l|}{ CV risk factors $(n=802)^{*}$} \\
\hline Family history of CV disease ${ }^{\dagger}$ & $326(41.5)$ \\
\hline Hypertension & $283(35.3)$ \\
\hline Smoking & $147(18.3)$ \\
\hline Diabetes & $96(12.0)$ \\
\hline Previous CV incident & $94(11.7)$ \\
\hline \multicolumn{2}{|l|}{ BMI $\left(\mathrm{kg} \mathrm{m}^{-2}\right) *(n=783)$} \\
\hline$<18.5$ & $14(1.8)$ \\
\hline $18.5-24.9$ & $344(43.9)$ \\
\hline $25-29.9$ & $302(38.6)$ \\
\hline $30+$ & $123(15.7)$ \\
\hline \multicolumn{2}{|l|}{ Physical activity ${ }^{\S}(n=802)$} \\
\hline Very good level & $192(23.9)$ \\
\hline Good level & $383(47.8)$ \\
\hline Poor level & $227(28.3)$ \\
\hline
\end{tabular}

CV, cardiovascular.

*Each factor was enquired about individually.

${ }^{\dagger} n=786$.

*When BMI and physical activity were taken into account, 30.7\% of individuals had two other classical CV risk factors; mean BMI was $25.9 \mathrm{~kg} \mathrm{~m}^{-2}$.

§very good level: walking over 30 min daily and taking part in a sporting activity at least once a week; good level: walking over 30 min daily or taking part in a sporting activity at least once a week; poor level: walking <30 min daily and not taking part in a sporting activity at least once a week.

Table 3 Aetiology, perception of disease, and fear of cholesterolassociated risks

\begin{tabular}{lc}
\hline & $n(\%)$ \\
\hline $\begin{array}{l}\text { Aetiology of disease, according to individual } \\
(n=802)\end{array}$ & \\
\hline Family trait & $351(43.8)$ \\
\hline Lifestyle & $171(21.3)$ \\
\hline Disturbance in metabolism & $108(13.5)$ \\
\hline Did not know & $56(7.0)$ \\
\hline Unexplained & $42(5.2)$ \\
\hline Poor quality food & $41(5.1)$ \\
\hline Other medication & $26(3.2)$ \\
\hline Lack of information & $7(0.9)$ \\
\hline Perception of disease $(n=802)$ & \\
\hline Normal after 45 years of age & $251(31.3)$ \\
\hline Worrying & $193(24.1)$ \\
\hline Invisible & $173(21.6)$ \\
\hline Restricting & $149(18.6)$ \\
\hline Did not know & $36(4.5)$ \\
\hline Fear of cholesterol-associated risks $(n=802)$ & \\
\hline Quite frightened & $338(42.1)$ \\
\hline Not really frightened & $184(22.9)$ \\
\hline Not at all frightened & $182(22.7)$ \\
\hline Very frightened & $83(10.3)$ \\
\hline Did not know & $15(1.9)$ \\
\hline
\end{tabular}


Table 4 Person to whom confidence in disease management was given, information sources used, beliefs concerning protection against cardiovascular risks, and frequency of medical consultation

\begin{tabular}{|c|c|}
\hline & $n(\%)$ \\
\hline \multicolumn{2}{|c|}{$\begin{array}{l}\text { In the management of the illness, person to whom } \\
\text { most confidence was given }(n=802)\end{array}$} \\
\hline Medical resources (doctor, medication) & $401(50.0)$ \\
\hline Self & $308(38.4)$ \\
\hline Person did not worry about it & $45(5.6)$ \\
\hline Someone close & $22(2.7)$ \\
\hline Luck or fate & $17(2.1)$ \\
\hline Did not know & $6(0.7)$ \\
\hline Other & $3(0.4)$ \\
\hline \multicolumn{2}{|l|}{$\begin{array}{l}\text { Information sources used to help } \\
\text { lower cholesterol }(n=802)\end{array}$} \\
\hline Medical recommendations & $534(66.6)$ \\
\hline Personal knowledge & $111(13.8)$ \\
\hline Person did not seek information & $46(5.7)$ \\
\hline Product labels & $45(5.6)$ \\
\hline Information from television, Internet, etc. & $29(3.6)$ \\
\hline Advice from someone close & $21(2.6)$ \\
\hline Did not know & $12(1.5)$ \\
\hline Other & $4(0.5)$ \\
\hline \multicolumn{2}{|c|}{ The best method to protect against CV risks $(n=802)$} \\
\hline Follow doctor's advice & $302(37.7)$ \\
\hline Practise a physical activity & $233(29.1)$ \\
\hline $\begin{array}{l}\text { Make compromises (e.g. to alternate } \\
\text { between rich and light meals) }\end{array}$ & $104(13.0)$ \\
\hline Take medication & $67(8.4)$ \\
\hline Eat 'anti-cholesterol' foods & $41(5.1)$ \\
\hline Not think about risks/ignore the risks & $22(2.7)$ \\
\hline Other & $21(2.6)$ \\
\hline Did not know & $12(1.5)$ \\
\hline \multicolumn{2}{|l|}{$\begin{array}{l}\text { Frequency of medical consultation } \\
\text { for the illness }(n=802)\end{array}$} \\
\hline Once every 3 months & $356(44.4)$ \\
\hline One or two times per year & $255(31.8)$ \\
\hline Once monthly & $139(17.3)$ \\
\hline Less than once a year & $38(4.7)$ \\
\hline Did not know & $14(1.7)$ \\
\hline
\end{tabular}

CV, cardiovascular.

the responses was ignored, 'being with family or friends' had the largest number of responses $(57.1 \%)$, followed by 'necessary function' (55.4\%), then 'a pleasurable activity for myself' (45.2\%) and 'a way of maintaining health and protecting myself against illness' (42.1\%). On analysing the first responses alone, four eating profiles were defined: the functional eater $(41 \%)$, the convivial eater $(21.5 \%)$, the hedonistic eater (20\%) and the prudent eater (17.5\%).

'The taste' was the most important reason behind choice of food; economic factors were of lesser importance (Table 6). Some $48.4 \%$ of the respondents declared themselves unwilling to change their diet even if they had more money $(n=802)$.

With regard to cooking frequency $(n=798)$, the majority $(42.4 \%)$ of individuals cooked at every meal;
Table 5 Influence and role of people in management of the disease

\begin{tabular}{lc}
\hline & $n(\%)$ \\
\hline The person who played the most important & \\
role in managing the illness $(n=802)$ & $543(67.7)$ \\
Self & $191(23.8)$ \\
Doctor & $39(4.9)$ \\
Someone in close circle & $26(3.2)$ \\
No-one & $3(0.4)$ \\
Did not know & \\
Role close circle played in following medical & $299(37.3)$ \\
recommendations ( $n=802)$ & $282(35.2)$ \\
Helped person to follow them & $77(9.6)$ \\
\hline Did not really help & $65(8.1)$ \\
\hline Person had no close circle & \\
\hline Recommendations would have been easier & $46(5.7)$ \\
to follow if person lived alone & $33(4.1)$ \\
\hline Forced person to follow them & \\
\hline Did not know &
\end{tabular}

Table 6 Factors affecting food consumption

\begin{tabular}{lll}
\hline \multirow{2}{*}{$\begin{array}{l}\text { Reason behind } \\
\text { food choices } \\
(2 \text { possible answers) }\end{array}$} & $\begin{array}{l}\text { Most important } \\
\text { reason }(n=802)\end{array}$ & $\begin{array}{l}\text { Second most important } \\
\text { reason }(n=778)\end{array}$ \\
\hline Taste & $278(34.7)$ & $230(29.6)$ \\
Effect on health & $154(19.2)$ & $139(17.9)$ \\
$\begin{array}{l}\text { Depends on time } \\
\text { and context }\end{array}$ & $134(16.7)$ & $87(11.2)$ \\
Habit & $133(16.6)$ & $138(17.7)$ \\
Price & $67(8.4)$ & $143(18.4)$ \\
Did not know & $24(3.0)$ & $29(3.7)$ \\
Advertisement & $12(1.5)$ & $12(1.5)$ \\
\hline
\end{tabular}

$25.9 \%$ cooked at least one meal per day; $12.5 \%$ cooked several meals per week; $5.0 \%$ cooked for special occasions; and $14.2 \%$ never cooked.

For food shopping $(n=801), 71.7 \%$ shopped one or two times per week; $10.5 \%$ shopped several times per month; $8.4 \%$ shopped every day; $2.9 \%$ shopped less often than several times per month; and $6.6 \%$ never shopped.

As for eating outside of the home $(n=799), 44.8 \%$ never did so; $34.0 \%$ did so one or two times per week; and $21.2 \%$ did so three times or more each week. Of those individuals that ate meals outside the home $(n=396)$, $34.8 \%$ did this with friends; $31.6 \%$ ate in a restaurant; $19.4 \%$ in an institutional setting (e.g. the work canteen); and $14.1 \%$ ate home-prepared food at the workplace.

\section{Adherence to a lipid-lowering diet}

Individuals considered that fatty or red meats, processed meat and butter were the foods to avoid most if hypercholesterolaemic; vegetables, fruit and fish were considered 
to be the foods to favour (Table 7). Dietary deviation occurred mainly during meals at friends and at home; in the majority of cases, this was dealt with by eating more lightly at later meals (Table 8). The two most important reasons why following the medically prescribed dietary rules is difficult $(n=802)$ were 'tastes and eating habits' (40.8\%) and 'being invited out' (24.4\%); however, 50.9\% of the individuals considered that their doctor's advice was quite easy to follow. Cheese, processed meat and cakes were the foods most likely to be eaten in dietary lapses. Moreover, cheese, cakes and snacks were particularly likely to be eaten despite their low initial ranking as food groups to be avoided (Table 9). No significant difference regarding dietary behaviours was found between urban and rural people.

For cheese consumption in those that liked it ( $n=729$ ), $43.8 \%$ continued to eat it without taking medical advice into account; $47.9 \%$ ate it occasionally (e.g. when invited out); and $8.4 \%$ did not eat it any more (even if invited out).

Using a hypothetical cheese-eating situation in the 'compliance with diet variable' meant that statistically, ' $n$ '

Table 7 Foods classified as to be avoided or favoured*

\begin{tabular}{|c|c|}
\hline & $n(\%)$ \\
\hline \multicolumn{2}{|l|}{ Foods to be avoided $(n=802)$} \\
\hline Fatty meat, red meat & $455(56.7)$ \\
\hline Processed meat (charcuterie) & $354(44.1)$ \\
\hline Butter & $312(38.9)$ \\
\hline Cheese & $211(26.3)$ \\
\hline Other & $201(25.1)$ \\
\hline Egg & $150(18.7)$ \\
\hline Cakes & $88(11.0)$ \\
\hline Dish with rich sauce & $83(10.3)$ \\
\hline Alcohol (wines and other alcohols) & $74(9.2)$ \\
\hline Snacks & $13(1.6)$ \\
\hline Did not know & $7(0.9)$ \\
\hline \multicolumn{2}{|l|}{ Foods to be favoured $(n=802)$} \\
\hline Vegetables & $534(66.6)$ \\
\hline Fruit & $429(53.5)$ \\
\hline Fish & $328(40.9)$ \\
\hline Green vegetables & $206(25.7)$ \\
\hline Other & $175(21.8)$ \\
\hline Starchy foods (rice, pasta) & $66(8.2)$ \\
\hline Water & $44(5.5)$ \\
\hline Did not know & $38(4.7)$ \\
\hline Cereals, bread & $31(3.9)$ \\
\hline Pulses & $22(2.7)$ \\
\hline 'Anti-cholesterol' products & $15(1.9)$ \\
\hline Hot drinks (tea, herbal teas) & $7(0.9)$ \\
\hline
\end{tabular}

*The patients were asked two questions: (1) 'Name three foods which should, in your opinion, be avoided when someone has a too high level of cholesterol?'; (2) 'Name three foods which should, in your opinion, be eaten regularly when someone has a too high level of cholesterol?'.

Each food was enquired about individually.
Table 8 Dietary deviation and ease of following recommended diet

\begin{tabular}{lc}
\hline & $n(\%)$ \\
\hline $\begin{array}{l}\text { Situations when dietary deviation } \\
\text { took place }(n=670)^{*}\end{array}$ \\
$\begin{array}{l}\text { During meals at friends } \\
\text { During meals at home }\end{array}$ \\
$\begin{array}{l}\text { While eating out } \\
\text { During snacking }\end{array}$ & $197(29.4)$ \\
\hline Other & $75(11.2)$ \\
During meals at work & $11(1.6)$ \\
\hline Did not know & $7(1.0)$ \\
How the individual dealt with dietary & $7(1.0)$ \\
deviations ( $n=670)^{*}$ & \\
Ate lightly at later meals & $264(39.4)$ \\
\hline Did not worry & $124(18.5)$ \\
\hline Promised self would not deviate the next day & $100(14.9)$ \\
\hline Planned ahead by eating lightly at preceding meal(s) & $67(10.0)$ \\
Took medication & $44(6.6)$ \\
\hline Did physical activity the next day & $43(6.4)$ \\
Did not know & $15(2.2)$ \\
\hline Other & $9(1.3)$ \\
Planned ahead by doing physical activity & $4(0.6)$ \\
the day before & \\
\hline
\end{tabular}

*One hundred and thirty-two individuals were not included (101 claimed to never deviate from the prescribed diet, and 31 did not know how often they deviated from diet).

Table 9 Foods eaten during dietary deviation compared with foods individuals believed should be avoided*

\begin{tabular}{llc}
\hline & \multicolumn{1}{l}{$n(\%)$} & \\
\cline { 2 - 3 } & $\begin{array}{l}\text { Foods eaten during } \\
\text { dietary deviations } \\
(n=670)^{\dagger}\end{array}$ & $\begin{array}{c}\text { Foods considered } \\
\text { 'to be avoided' } \\
(n=802)\end{array}$ \\
\hline Cheese & $337(50.3)$ & $211(26.3)$ \\
$\begin{array}{l}\text { Processed meat } \\
\text { (charcuterie) }\end{array}$ & $262(39.1)$ & $354(44.1)$ \\
Cakes & $221(33.0)$ & $88(11.0)$ \\
Dish with rich sauce & $188(28.1)$ & $83(10.3)$ \\
Fatty meat, red meat & $161(24.0)$ & $745(56.7)$ \\
Alcohol (wines & $154(23.0)$ & $13(1.6)$ \\
and other alcohols) & $140(20.9)$ & $312(38.9)$ \\
Snacks & $118(17.6)$ & $150(18.7)$ \\
Butter & $118(17.6)$ & $201(25.1)$ \\
Egg & $52(7.8)$ & $7(0.9)$ \\
Other & $6(0.9)$ & \\
Did not know & &
\end{tabular}

*Each food was enquired about separately.

†One hundred and thirty-two individuals were not included (101 claimed to never deviate from the prescribed diet, and 31 did not know how often they deviated from diet).

was reduced to 729 . This was constructed with four variables, and excluded those who did not like cheese (see Materials and methods). Individuals classified 
Table 10 Association between compliance with diet and lipid-lowering medication

\begin{tabular}{|c|c|c|c|}
\hline & $\begin{array}{l}\text { Took lipid-lowering } \\
\text { medication (\%) }\end{array}$ & $\begin{array}{l}\text { Did not take } \\
\text { lipid-lowering } \\
\text { medication (\%) }\end{array}$ & $P$ \\
\hline$(n=729)$ & $476(65)$ & $253(35)$ & $<0.05$ \\
\hline $\begin{array}{l}\text { Complied } \\
\text { with diet }\end{array}$ & $244(51)$ & 89 (35) & \\
\hline $\begin{array}{l}\text { Did not comply } \\
\text { with diet }\end{array}$ & 232 (49) & $164(65)$ & \\
\hline
\end{tabular}

themselves as good (11\%), pretty good (35\%), pretty poor $(39 \%)$ and poor (15\%) regarding diet compliance; this was collapsed into $46 \%$ compliance and $54 \%$ noncompliance. A significant association was found between compliance with diet and use of lipid-lowering medication (Table 10). In addition, compliance with diet was neither correlated with gender, nor area of residence.

\section{Discussion}

This survey is the first large-scale detailed sociodemographic and socioeconomic study of the French hypercholesterolaemic population (defined by a total cholesterol level above $2 \mathrm{~g} \mathrm{~L}^{-1}-5.13 \mathrm{~mm}$, according to the French guidelines). Within the limitations imposed by the survey type, it provides a useful insight into this population group.

The initial difficulties with recruitment, and the final inclusion level of only $8 \%$ as opposed to the intended $20 \%$, could indicate that a section of the French population is unaware of being hypercholesterolaemic. This speculated unaware hypercholesterolaemic population may reside in males aged $<45$ years old: blood testing is infrequent in this population group. In addition, hypercholesterolaemic individuals who are aware of their disease, but who have not yet been prescribed medication, may not consider themselves to be truly hypercholesterolaemic and, as a result, may have declined to answer the survey. The same could be true of individuals aged $>45$ years who consider that it is normal to have hypercholesterolaemia from middle-age onwards. Furthermore, as with any survey, there is also the possibility of selfexclusion occurring as a result of a lack of time or interest, or other personal factors.

The wide discrepancy between the expected level of recruitment and the actual level achieved may also have resulted from differences between the design of the present study and that of the reference used (Ferrieres et al., 2009). Ferrieres et al. (2009) investigated trends in dyslipidaemias by carrying out a representative survey of the general population in three French cities. However, a narrower age range for inclusion was imposed (3564 years) and blood testing was carried out. These major differences in design make comparison between the results more difficult. First, it can be assumed that the level of unknown hypercholesterolaemia is higher in younger adults, thus reducing the percentage of self-reporting in the present study. Second, because blood testing is a far more accurate method of assessing hypercholesterolaemia than is self-reporting, Ferrieres et al. (2009) probably detected a more reliable frequency. However, an important selection bias may have existed in that study because the participants were required to be available for a questionnaire, physical examination and blood testing.

In terms of gender, the present sample was representative of the French population (INSEE, 2008). However, as expected when selecting hypercholesterolaemic individuals, the mean age of participants was above that of the general population (INSEE, 2008). Perhaps as a reflection of this older population, and the generally higher level of being overweight and obesity in hypercholesterolaemic people (Denke et al., 1993, 1994), the mean body mass index (BMI) was higher (Charles et al., 2008).

Although the overall sample education level appears low, this is probably a result of the older population not having required tertiary education certification to progress in their work in the 1970s and 1980s. Indeed, compared to the overall French population (INSEE, 2008), when divided into age groups, the education level of the individuals in the sample was high. This could be considered as unexpected because a high level of consumption of fatty foods has often been found especially in the lower social levels (Corbeau, 1995; Bruckert et al., 2005; Czernichow et al., 2005). This may indicate that the speculated unaware hypercholesterolaemic population resides not only in under males aged $<45$ years, but also in less educated people in general.

The French census only records the socioprofessional category of the household head; in the present study, however, not only family heads, but also spouses, other family members, people who lived in shared accommodation, etc. were interviewed. It was thus impossible to choose who should be considered as the 'official' head of the household.

A quarter of the sample perceived their hypercholesterolaemia to be worrying, and 52\% were frightened to some extent by the associated risks. However, 57\% of individuals did not know their cholesterol level, 31\% considered the disease to be normal beyond the age of 45 years, and $22 \%$ considered it to be invisible. In addition, $46 \%$ were not frightened or not really frightened by the associated risks. These combined results may indicate that a substantial number of hypercholesterolaemic individuals have a tendency to consider the disease as trivial.

In terms of behaviour and attitudes surrounding food and eating, the strong preference given for communal 
eating is not unexpected (Rozin et al., 2006); of more interest is the lesser emphasis given to the pleasurable aspects of food, and the strong 'functional' response. This may be a result of the older sample population placing more emphasis on family and friendship ties than personal gratification. The older population might also explain the fact that $14 \%$ of the sample never cooked and 7\% never shopped for food. One could expect that, because $50 \%$ of the sample was retired and $51 \%$ were living as a couple, certain individuals would not be involved in food preparation at any level. The results showing that 'the taste' is the major factor involved in food choice are entirely in line with previous studies (Rozin et al., 1999; Pettinger et al., 2004); this has been shown to be a very distinct French characteristic, in comparison with, for example, the American population.

The lack of response to the option of eating mainly representing ethical, political and ecological convictions is probably a reflection of French cultural attitudes to food. It is unsurprising because the lack of interest in expressing such convictions via dietary choice in French people has already been reported (Pettinger et al., 2004).

The results for compliance with diet are of particular interest. As was noted in the initial sociological study (Fournier \& Poulain, 2008), convivial circumstances, such as meals with friends and festive occasions, can make dietary compliance difficult. Faced with a food that they liked but which they were recommended to restrict, $44 \%$ of the cheese-liking subgroup $(n=729)$ continued to eat it. In addition, in the 'compliance with diet' variable, $54 \%$ admitted that they did not comply with the recommended lipid-lowering diet. This could be an indication of pleasure (or habit) over-riding prudence. Of those that generally did comply with dietary recommendations, more individuals took lipid-lowering medication than not. This finding is important because it is often assumed that patients on medication have a tendency to relax their vigilance concerning their diet, relying on the drug to take care of the cholesterol problem. In terms of medical and dietetic practice, this could mean that a change in expectation from the healthcare practitioner (with more encouragement being given to the patient to persist with simultaneous dietary and pharmaceutical measures) would result in better management of blood cholesterol.

Before the present study began, no other French data of this type had been produced. However, in 2008, the From The Heart study (Hobbs et al., 2008) reported the findings from their intercontinental survey of cholesterol management. This survey had a similar method to the present one (i.e. a telephone survey with quotas applied), and it reported the demographic details of 200 French hypercholesterolaemic patients. In the From The Heart study, 52\% of French hypercholesterolaemic patients stated that they were 'not concerned about being diagnosed with high cholesterol'. This directly supports the suggestion made in the present study that a large proportion of patients have a tendency to consider hypercholesterolaemia as a trivial disease.

Despite an extensive literature search being made, only one other study reporting specific details about compliance or not with both diet and medication in hypercholesterolaemia was found. In the Women's Health Initiative (Hsia et al., 2002), comprising a cross-sectional study of 91627 post-menopausal American women, it was found that those women who had hypercholesterolaemia and needed lipid-lowering medication, and those who had high low-density lipoprotein cholesterol levels, were more likely to comply with dietary and lifestyle recommendations than women who did not have hypercholesterolaemia. It was suggested that being aware of high cholesterol was associated with lifestyle changes. This partly supports the results reported in the present study, although there are great cultural differences between the populations. In hypercholesterolaemia, factors affecting adherence to medical recommendations can include a poor understanding of the disease and cardiovascular risk factors (Hobbs et al., 2008); IQ, complicated drug regimes, depression, anxiety (Stilley et al., 2004); and misunderstandings in doctor/patient communication, caused by the use of medical jargon and inadequate responses to questions (Durack-Bown et al., 2003). In the light of the present findings, these factors could be usefully studied in the future in the context of both diet and medication.

This survey has several limitations. First, the nonrandom quota method has inherent bias (Fourrier-Reglat \& Jutand, 2006). Second, patient self-reporting always carries the risk of under- or over-estimations being made (Drummond et al., 2003); it is unlikely that self-reported height and weight, for example, give an accurate BMI (Yannakoulia et al., 2006). Third, no post-survey check was carried out. Finally, the self-selection of individuals who considered themselves to be hypercholesterolaemic could have resulted in the inclusion of more severely affected and more motivated people, thus biasing the results. However, by using an anonymised telephone survey, the bias introduced in surveys carried out in person by healthcare professionals (during which patients may be more tempted to give answers that they think the professional would like to hear) was reduced.

There are several clinical implications resulting from this study. First, because the perception of risk linked to hypercholesterolaemia was low in a proportion of individuals already diagnosed with the disease, doctors and dieticians could be advised to place greater emphasis on educating existing patients about the serious long-term cardiovascular effects of the illness, and to continue encouraging them to persist with treatment. The finding 
that compliance with both dietary and medicinal measures was already practised by a large percentage of individuals can be used to support patients in their efforts to follow recommendations. Second, because it appears that a significant proportion of the population could be unaware of being affected, measures may be required to raise awareness and encourage screening in more at-risk individuals, particularly younger men. However, because the initial treatment involves dietary alterations, once hypercholesterolaemia is diagnosed, the healthcare professional needs to determine the individual patient's overall attitude to food, lifestyle and social situation to be able to give appropriate dietary advice that will actually be followed. This may involve taking the time to discern the patient's perception of risk associated with hypercholesterolaemia, their degree of confidence in what the professional says, their attitudes towards eating in a social context, their eating habits, and their economic situation. Depending on the country-specific and/or the individual cultural context, this would also involve being sensitive to the conviviality and pleasure surrounding eating behaviour, as well as the emphasis placed on taste.

In conclusion, the present survey provides extensive and detailed information on sociodemographic characteristics, disease perception, and dietary beliefs and practices in a large sample of hypercholesterolaemic individuals. It has shown that, contrary to general expectations, a substantial number of individuals comply simultaneously with dietary and pharmaceutical recommendations. These findings have direct implications for the management of hypercholesterolaemia.

\section{Acknowledgments}

The authors thank the individuals who participated in the survey. Catriona Holmes (Paris), provided medical writing services.

\section{Conflict of interests, source of funding and authorship}

TF and JPP declares having received honoraria from Unilever. EB declares having received honoraria from Unilever and Danone. AP is employed by Unilever, France. The THEMA study was commissioned by the New French Society for Atherosclerosis (la Nouvelle Société Française d'Athérosclérose), and funded by Unilever France.

TF, EB, SC, AP and JPP contributed to the planning of the study, the supervision of the questionnaire design, and the analysis of the data. TF supervised the data collection and analysis. All authors contributed to the preparation of the manuscript. All authors critically reviewed the manuscript and approved the final version submitted for publication.

\section{References}

AFSSAPS - Agence Française de Sécurité Sanitaire des Produits de Santé (2005) Recommandations de bonne pratique. Prise en charge thérapeutique du patient dyslipidémique. Recommandations. Saint Denis: AFSSAPS.

Bruckert, E., Czernichow, S., Bertrais, S., Paillard, F., Tichet, J., Galan, P., Castetbon, K. \& Hercberg, S. (2005) Blood lipid and lipoprotein levels: relationships with educational level and region of residence in the French SU.VI.MAX study. Prev. Med. 40, 803-811.

Charles, M.A., Eschwege, E. \& Basdevant, A. (2008) Monitoring the obesity epidemic in France: the Obepi surveys 19972006. Obesity (Silver Spring) 16, 2182-2186.

Corbeau, J.P. (1995) L'imaginaire du gras associé à divers types de consommation de gras et les perceptions de leurs qualités. In Agro-alimentaire: une économie de la qualité. eds F. Nicholaïs \& E. Valceschini, pp. 93-103. Paris: INRA-Economica.

Czernichow, S., Bruckert, E., Oppert, J.M., Bertrais, S., Paillard, F., Astorg, P., Arnault, N., Galan, P. \& Hercberg, S. (2005) Intake of added oils and fats among middle-aged French adults: relationships with educational level and region of residence. J. Am. Diet. Assoc. 105, 1889-1894.

Denke, M.A., Sempos, C.T. \& Grundy, S.M. (1993) Excess body weight. An under-recognized contributor to high blood cholesterol levels in white American men. Arch. Intern. Med. 153, 1093-1103.

Denke, M.A., Sempos, C.T. \& Grundy, S.M. (1994) Excess body weight. An under-recognized contributor to dyslipidemia in white American women. Arch. Intern. Med. 154, 401-410.

Desrosieres, A. (1998) The Politics of Large Numbers: A History of Statistical Reasoning. Cambridge, MA: Harvard University Press.

Drummond, S., Kirk, T., Jackson, J., Hendry, J., Panton, S. \& Gray, F. (2003) Effectiveness of dietary advice given by community dietitians to men with elevated blood cholesterol in a clinical setting: a pilot study. J. Hum. Nutr. Diet. 16, 81-83.

Durack-Bown, I., Giral, P., d'Ivernois, J.F., Bazin, C., Chadarevian, R., Benkritly, A. \& Bruckert, E. (2003) Patients' and physicians' perceptions and experience of hypercholesterolaemia: a qualitative study. Br. J. Gen. Pract. 53, 851-857.

Ferrieres, J., Bongard, V., Dallongeville, J., Arveiler, D., Cottel, D., Haas, B., Wagner, A., Amouyel, P. \& Ruidavets, J.B. (2009) Trends in plasma lipids, lipoproteins and dyslipidaemias in French adults, 1996-2007. Arch. Cardiovasc. Dis. 102, 293-301.

Fournier, T. \& Poulain, J.P. (2008) Les déterminants sociaux du non-suivi des régimes alimentaires. Le cas des patients hypercholestérolémiques. Cah. Nutr. Diét. 43, 97-104.

Fourrier-Reglat, A. \& Jutand, M. (2006) Initiation aux méthodes de sondage, application à la pharmaco-épidémiologie, 1st edn. Bordeaux: ARME-Pharmacovigilance.

Grundy, S.M., Cleeman, J.I., Merz, C.N., Brewer, H.B. Jr., Clark, L.T., Hunninghake, D.B., Pasternak, R.C., Smith, S.C. 
Jr., Stone, N.J. \& National Heart, Lung, and Blood Institute; American College of Cardiology Foundation; American Heart Association (2004) Implications of recent clinical trials for the National Cholesterol Education Program Adult Treatment Panel III Guidelines. Circulation 110, 227-239.

Hobbs, F.D., Erhardt, L.R. \& Rycroft, C. (2008) The From The Heart study: a global survey of patient understanding of cholesterol management and cardiovascular risk, and physician-patient communication. Curr. Med. Res. Opin. 24, 1267-1278.

Hsia, J., Rodabough, R., Rosal, M.C., Cochrane, B., Howard, B.V., Snetselaar, L., Frishman, W.H. \& Stefanick, M.L. (2002) Compliance with National Cholesterol Education Program dietary and lifestyle guidelines among older women with self-reported hypercholesterolemia. The Women's Health Initiative. Am. J. Med. 113, 384-392.

INSEE - Institut National de la Statistique et des Etudes Economiques (2008) Bilan Démographique 2007. Paris: INSEE.

McQueen, M.J., Hawken, S., Wang, X., Ounpuu, S., Sniderman, A., Probstfield, J., Steyn, K., Sanserson, J.E., Hasani, M., Volkova, E., Kazmi, K., Yusuf, S. \& INTERHEART Study Investigators (2008) Lipids, lipoproteins, and apolipoproteins as risk markers of myocardial infarction in 52 countries (the INTERHEART study): a case control study. Lancet 372, 224-233.

Pettinger, C., Holdsworth, M. \& Gerber, M. (2004) Psychosocial influences on food choice in Southern France and Central England. Appetite 42, 307-316.
Poulain, J.P. (2002) The contemporary diet in France: 'De-structuration' or from commensalism to 'vagabond feeding'. Appetite 39, 43-55.

Richard, J.L. (1987) [Coronary risk factors. The French paradox]. Arch. Mal. Coeur Vaiss. 80 Spec No, 17-21.

Rozin, P., Fischler, C., Imada, S., Sarubin, A. \& Wrzesniewski, A. (1999) Attitudes to food and the role of food in life in the U.S.A., Japan, Flemish Belgium and France: possible implications for the diet-health debate. Appetite 33, 163-180.

Rozin, P., Fischler, C., Shields, C. \& Masson, E. (2006) Attitudes towards large numbers of choices in the food domain: a cross-cultural study of five countries in Europe and the USA. Appetite 46, 304-308.

Stilley, C.S., Sereika, S., Muldoon, M.F., Ryan, C.M. \& Dunbar-Jacob, J. (2004) Psychological and cognitive function: predictors of adherence with cholesterol lowering treatment. Ann. Behav. Med. 27, 117-124.

The Emerging Risk Factors Collaboration, Di Angelantonio, E., Sarwar, N., Perry, P., Kaptoge, S., Ray, K.K., Thompson, A., Wood, A.M., Lewington, S., Sattar, N., Packard, C.J., Collins, R., Thompson, S.G. \& Danesh, J. (2009) Major lipids, apolipoproteins, and risk of vascular disease. JAMA 302, 1993-2000.

Yannakoulia, M., Panagiotakos, D.B., Pitsavos, C. \& Stefanadis, C. (2006) Correlates of BMI misreporting among apparently healthy individuals: the ATTICA study. Obesity (Silver Spring) 14, 894-901. 